\title{
Performance of the Pediatric Glasgow Coma Scale Score in the Evaluation of Children With Blunt Head Trauma
}

Dominic A. Borgialli, DO, MPH, Prashant Mahajan, MD, MPH, MBA, John D. Hoyle, Jr., MD, Elizabeth C. Powell, MD, Frances M. Nadel, MD, Michael G. Tunik, MD, Adele Foerster, MSN, Lydia Dong, MS, Michelle Miskin, MS, Peter S. Dayan, MD, MSc, James F. Holmes, MD, MPH, Nathan Kuppermann, MD, MPH, for the Pediatric Emergency Care Applied Research Network (PECARN)

\begin{abstract}
Objective: The objective was to compare the accuracy of the pediatric Glasgow Coma Scale (GCS) score in preverbal children to the standard GCS score in older children for identifying those with traumatic brain injuries (TBIs) after blunt head trauma.

Methods: This was a planned secondary analysis of a large prospective observational multicenter cohort study of children with blunt head trauma. Clinical data were recorded onto case report forms before computed tomography (CT) results or clinical outcomes were known. The total and component GCS scores were assigned by the physician at initial emergency department evaluation. The pediatric GCS was used for children $<2$ years old and the standard GCS for those $\geq 2$ years old. Outcomes were TBI visible on CT and clinically important TBI (ciTBI), defined as death from TBI, neurosurgery, intubation for more than 24 hours for the head injury, or hospitalization for 2 or more nights for the head injury in association with TBI on CT. We compared the areas under the receiver operating characteristic (ROC) curves between age cohorts for the association of GCS and the TBI outcomes.
\end{abstract}

From the Department of Emergency Medicine, Hurley Medical Center (DAB), Flint, MI; the Department of Emergency Medicine, University of Michigan (DAB), Ann Arbor, MI; the Department of Pediatrics, Division of Pediatric Emergency Medicine, Wayne State University School of Medicine (PM), Detroit, MI; the Division of Emergency Medicine, Helen DeVos Children's Hospital, and the Department of Emergency Medicine, Michigan State University (JDH), East Lansing, MI; the Departments of Emergency Medicine and Pediatrics, Western Michigan University School of Medicine (JDH), Kalamazoo, MI; the Department of Pediatrics, Division of Pediatric Emergency Medicine, Northwestern University's Feinberg School of Medicine (ECP), Chicago, IL; the Department of Pediatrics, Division of Pediatric Emergency Medicine, University of Pennsylvania School of Medicine (FMN), Philadelphia, PA; the Departments of Pediatrics and Emergency Medicine, NYU School of Medicine (MGT), New York, NY; Silver Spring Emergency Physicians, Holy Cross Hospital (AF), Silver Spring, MD; the Department of Pediatrics, University of Utah and PECARN Data Coordinating Center (LD, MM), Salt Lake City, UT; the Division of Pediatric Emergency Medicine, Morgan Stanley Children's Hospital, Columbia University College of Physicians and Surgeons (PSD), New York, NY; the Department of Emergency Medicine (JFH, NK) and the Department of Pediatrics (NK), University of California at Davis School of Medicine, Sacramento, CA.

Received December 19, 2015; revision received April 14, 2016; accepted April 22, 2016.

Presented in part at the Pediatric Academic Societies Annual Meeting, Boston, MA, May 2009; and the Society for Academic Emergency Medicine Annual Meeting, New Orleans, LA, May 2009.

Author contributions: Drs. Kuppermann, Holmes, and Borgialli conceived of the study; Dr. Kuppermann obtained grant funding for the study; Ms. Dong and Ms. Miskin conducted the data analysis; Ms. Dong, Ms. Miskin, and Drs. Kuppermann, Holmes, and Borgialli interpreted the data; Drs. Borgialli and Kuppermann drafted the manuscript; and all authors critically revised the manuscript.

This work was supported by a grant from the Health Resources and Services Administration/Maternal and Child Health Bureau (HRSA/MCHB), Division of Research, Education, and Training, and the Emergency Medical Services of Children (EMSC) Program (R40MC02461). This project was also supported in part by HRSA, MCHB, and the EMSC Network Development Demonstration Program under cooperative agreements U03MC00008, U03MC00001, U03MC00003, U03MC00006, U03MC00007, U03MC22684, and U03MC22685. The information or content and conclusions are those of the author and should not be construed as the official position or policy of, nor should any endorsements be inferred by HRSA, HHS, or the U.S. Government.

The authors have no potential conflicts to disclose.

Supervising Editor: Jennifer Walthall, MD, MPH.

Address for correspondence: Nathan Kuppermann, MD, MPH; e-mail: nkuppermann@ucdavis.edu. 
Results: We enrolled 42,041 patients, of whom 10,499 (25.0\%) were $<2$ years old. Among patients $<2$ years, $313 / 3,329(9.4 \%$, 95\% confidence interval $[\mathrm{CI}]=8.4 \%$ to $10.4 \%)$ of those imaged had TBIs on CT and $146 / 10,499(1.4 \%, 95 \% \mathrm{CI}=1.2 \%$ to $1.6 \%)$ had ciTBIs. In patients $\geq 2$ years, $773 / 11,977(6.5 \%, 95 \%$ $\mathrm{CI}=6.0 \%$ to $6.9 \%)$ of those imaged had TBIs on CT and $572 / 31,542(1.8 \%, 95 \% \mathrm{CI}=1.7 \%$ to $2.0 \%)$ had ciTBIs. For the pediatric GCS in children <2 years old, the area under the ROC curve was $0.61(95 \%$ $\mathrm{CI}=0.59$ to 0.64$)$ for $\mathrm{TBI}$ on $\mathrm{CT}$ and $0.77(95 \% \mathrm{CI}=0.73$ to 0.81$)$ for ciTBI. For the standard GCS in older children, the area under the ROC curve was $0.71(95 \% \mathrm{CI}=0.70$ to 0.73 ) for TBI on CT scan and 0.81 $(95 \% \mathrm{CI}=0.79$ to 0.83$)$ for ciTBI.

Conclusions: The pediatric GCS for preverbal children was somewhat less accurate than the standard GCS for older children in identifying those with TBI on CT. However, the pediatric GCS for preverbal children and the standard GCS for older children were equally accurate for identifying ciTBI.

ACADEMIC EMERGENCY MEDICINE 2016;23:878-884 (c) 2016 by the Society for Academic Emergency Medicine

$\mathrm{T}$ he Glasgow Coma Scale (GCS) score is one of the most recognized and widely used tools for assessment of level of consciousness and severity of mental status alteration in patients with traumatic brain injuries (TBIs) and a variety of other neurologic conditions. The GCS score is calculated by adding the scores of the following three components: eye response (range $=1-4$ ), verbal response (range $=1-5$ ), and motor response (range $=1-6$ ). ${ }^{1}$ The GCS score is used to categorize TBI severity as mild, moderate, or severe; is a component of outcome prediction models; and is used to guide therapy. ${ }^{2}$

Due to the need for verbal interaction, clinicians cannot use the standard GCS score to appropriately assess preverbal children. Therefore, the pediatric GCS score is a modified GCS score for use in preverbal children. The pediatric GCS uses age-appropriate modifications to account for developmental differences in verbal, motor, and cognitive abilities (Table 1$)^{3-6}$

There has been very limited prospective study, however, of the accuracy of the pediatric GCS in identifying young children with TBIs, particularly in the emergency department (ED) setting. Our prior research at a single ED suggests that the pediatric GCS score in children 2 years and younger compares favorably with the standard GCS when used for the evaluation of blunt head trauma in older children. ${ }^{7}$ These data, however, require further validation in a larger study.

We previously conducted a large prospective multicenter study to develop and validate prediction rules for identifying children with clinically important TBIs (ciTBIs) after blunt head trauma. ${ }^{8}$ The standard GCS score for older children and the pediatric GCS score for children younger than 2 years were prospectively collected at ED presentation.

In the current subanalysis of the parent study, we sought to compare the performance of the pediatric and standard GCS scores for identifying children with TBIs on computed tomography (CT) and ciTBIs. The secondary objective was to compare the performance of the individual components of the standard and pediatric GCS scores. We hypothesized that the pediatric GCS score in preverbal children would perform as well as the standard GCS score in verbal children for identifying those with TBIs.

\section{METHODS}

\section{Study Design}

This was a planned secondary analysis of a large prospective observational multicenter study of children with blunt head trauma. Information about and methods

\section{Table 1}

Comparisons of the Components of the Standard and Pediatric GCS

\begin{tabular}{|c|c|c|c|}
\hline & Score & Standard GCS & Pediatric GCS \\
\hline Eye opening & $\begin{array}{l}4 \\
3 \\
2 \\
1\end{array}$ & $\begin{array}{l}\text { Spontaneous } \\
\text { To voice } \\
\text { To pain } \\
\text { None }\end{array}$ & $\begin{array}{l}\text { Spontaneous } \\
\text { To voice } \\
\text { To pain } \\
\text { None }\end{array}$ \\
\hline Verbal response & $\begin{array}{l}5 \\
4 \\
3 \\
2 \\
1\end{array}$ & $\begin{array}{l}\text { Oriented } \\
\text { Confused } \\
\text { Inappropriate words } \\
\text { Incomprehensible sounds } \\
\text { None }\end{array}$ & $\begin{array}{l}\text { Coos/babbles } \\
\text { Irritable/cries } \\
\text { Cries to pain } \\
\text { Moans } \\
\text { None }\end{array}$ \\
\hline Motor response & $\begin{array}{l}6 \\
5 \\
4 \\
3 \\
2 \\
1\end{array}$ & $\begin{array}{l}\text { Follows commands } \\
\text { Localizes pain } \\
\text { Withdraws to pain } \\
\text { Abnormal flexure posturing } \\
\text { Abnormal extension posturing } \\
\text { None }\end{array}$ & $\begin{array}{l}\text { Spontaneous movement } \\
\text { Withdraws to touch } \\
\text { Withdraws to pain } \\
\text { Abnormal flexure posturing } \\
\text { Abnormal extension posturing } \\
\text { None }\end{array}$ \\
\hline
\end{tabular}


of the parent study population are described elsewhere. ${ }^{8}$ The methods specific to this study are described below. The study was approved at each site's institutional review board.

\section{Study Setting and Population}

The study was conducted between June 2004 and September 2006 at 25 pediatric EDs in the Pediatric Emergency Care Applied Research Network (PECARN). We included patients younger than 18 years who were evaluated in any PECARN participating ED after a history of nontrivial blunt head trauma. For this subanalysis, we excluded children who did not have GCS scores recorded at the time of the initial ED evaluation.

\section{Study Protocol}

The ED clinician completed a history and physical examination on each patient and recorded the data onto a case report form before CT scan results or clinical outcomes were known. Two faculty or fellow physicians independently evaluated a convenience sample of 1,443 patients with all three GCS components documented by both evaluators to determine the interobserver agreement for GCS. The second evaluation was completed within 1 hour of the first evaluation. We used the pediatric GCS score $^{6}$ to evaluate children younger than 2 years and the standard GCS score $^{1}$ for children 2 years and older.

\section{Measurements}

We compared the pediatric and standard GCS scores against two different outcomes: TBI on CT and ciTBI. As per the parent study, TBI on CT was defined by the presence of intracranial blood, pneumocephalus, cerebral edema, diastasis of the skull, or skull fracture depressed by at least the width of the skull. ciTBI was defined as death from TBI, a neurosurgical procedure, intubation for more than 24 hours for the head injury, or hospitalization for $\geq 2$ nights because of the head injury in association with TBI on CT.

\section{Follow-up Procedures}

The records of patients admitted to the hospital were reviewed by research coordinators for outcome determination. For all patients discharged home from the ED, we conducted telephone or mail follow-up 790 days after the ED visit to ascertain for patients with missed TBIs. For those we could not reach by telephone or mail follow-up, we reviewed the medical records, ED process improvement records, trauma registries, and county morgue records to ensure that no discharged patient was subsequently diagnosed with a ciTBI.

\section{Data Analysis}

Each variable was described for the pediatric and standard GCS cohorts using counts, percentages, and 95\% confidence intervals (CIs) for categorical variables and the median and interquartile ranges (IQRs; 25th-75th percentile) for continuous variables. We compared the patient characteristics, rate of TBI on CT, and rate of ciTBI by GCS cohort using rate differences with $95 \%$ CI.

We used receiver operating characteristic (ROC) curves with $95 \%$ CI to compare the total GCS score and its individual components against TBI on CT and ciTBI between the two GCS cohorts. To assess for interobserver agreement, we calculated the kappa statistics for the pediatric and standard GCS cohorts using the FleissCohen weighted kappa with standard quadratic weights. The 95\% confidence limits were calculated using normal approximation methods. A 95\% lower confidence limit greater than 0.4 denoted at least moderate agreement. ${ }^{9}$ All analyses were conducted using SAS version 9.3.

\section{RESULTS}

The parent study enrolled 43,904 eligible patients. A total of $42,041(95.8 \%)$ patients met the inclusion/exclusion criteria of the parent study, except that all patients with all GCS scores were eligible for the current study. Those with GCS scores available compose the study population for the current analysis. There were 10,499 patients in the pediatric GCS group of whom $3,329(31.7 \%)$ had CT scans performed in the ED. In the standard GCS group, there were 31,542 patients of whom 11,977 (38.0\%) had CT scans performed in the ED. The baseline characteristics between the pediatric and standard GCS cohorts are presented in Table 2. The median age of the pediatric GCS cohort was 1.0 years (IQR $=0.5$ to 1.5 years) and for the standard GCS cohort was 8.6 years (IQR $=4.5$ to 13.7). Of note, approximately $2 \%$ of the patients had GCS scores between 3 and 13 .

Among the children imaged with $\mathrm{CT}$, the rate of TBI on CT was significantly higher in children who were in the pediatric GCS cohort $(313 / 3,329$ [9.4\%, 95\% $\mathrm{CI}=8.4 \%$ to $10.4 \%$ ]) compared to those in the standard GCS cohort $(773 / 11,977[6.5 \%, 95 \% \mathrm{CI}=6.0 \%$ to $6.9 \%]$; risk difference $=2.9 \%, 95 \% \mathrm{CI}=1.9 \%$ to $4.0 \%$ ). The rate of ciTBI, however, was lower in the pediatric GCS cohort $(146 / 10,499$ [1.4\%, 95\% CI $=1.2 \%$ to $1.6 \%])$ compared to those in the standard GCS cohort (572/31,542 [1.8\%, 95\% $\mathrm{CI}=1.7 \%$ to $2.0 \%$ ]; risk difference $=-0.4 \%$, $95 \%$ $\mathrm{CI}=-0.7 \%$ to $-0.2 \%$ ), although the difference between groups was small and likely not clinically relevant.

The area under the ROC curve for the association between the GCS score and TBI on CT was $0.61(95 \%$ $\mathrm{CI}=0.59$ to 0.64$)$ in the younger cohort and $0.71(95 \%$ $\mathrm{CI}=0.70$ to 0.73 ) for the older cohort (Figure 1). The area under the ROC curve for the association between the GCS score and ciTBI was $0.77(95 \% \mathrm{CI}=0.73$ to 0.81 ) for the younger cohort and $0.81(95 \% \mathrm{CI}=0.79$ to 0.83) in the older cohort (Figure 2). The association between the areas under the ROC curves for the individual components of the pediatric and standard GCS scores (eye, verbal, motor) and TBI on CT and ciTBI are presented in Figures 3 and 4, respectively. For both TBI outcomes, the areas under the ROC curves for the total GCS score were most similar to those for the verbal component of the GCS score for the pediatric and standard GCS cohorts.

The interobserver agreements as measured by the kappa statistics for the pediatric and standard GCS cohorts are shown in Table 3. In each GCS cohort, the total GCS score and all individual GCS score components met the criteria for at least moderate interobserver agreement (kappa 95\% lower confidence limit >0.4). 
Table 2

Comparison of Pediatric GCS and Standard GCS Cohorts

\begin{tabular}{|c|c|c|c|}
\hline Characteristic & $\begin{array}{c}\text { Pediatric GCS (Age }<2 \text { y) } \\
n=10,499, n(\%) ; 95 \% \mathrm{Cl}\end{array}$ & $\begin{array}{c}\text { Standard GCS (Age } \geq 2 \mathrm{y}), \\
n=31,542, n(\%) ; 95 \% \mathrm{Cl}\end{array}$ & Difference, \% (95\% Cl) \\
\hline Age (y), median (IQR) & $1.0(0.5-1.5)$ & $8.6(4.5-13.7)$ & \\
\hline Male & $5,762(54.9 \%) ; 53.9 \%-55.8 \%$ & $20,446(64.8 \%) ; 64.3 \%-65.4 \%$ & $-9.9 \%(-11.0$ to $-8.9 \%)$ \\
\hline \multicolumn{4}{|c|}{ Severity of injury mechanism* } \\
\hline Mild & $1,514 / 10,390(14.6 \%) ; 13.9 \%-15.3 \%$ & $5,441 / 31,332(17.4 \%) ; 16.9 \%-17.8 \%$ & $-2.8 \%(-3.6$ to $-2.0 \%)$ \\
\hline Moderate & $6,549 / 10,390(63.0 \%) ; 62.1 \%-64.0 \%$ & $21,820 / 31,332(69.6 \%) ; 69.1 \%-70.2 \%$ & $-6.6 \%(-7.7 \%$ to $-5.6 \%)$ \\
\hline Severe & $2,327 / 10,390(22.4 \%) ; 21.6 \%-23.2 \%$ & $4,071 / 31,332(13.0 \%) ; 12.6 \%-13.4 \%$ & $9.4 \%(8.5 \%$ to $10.3 \%)$ \\
\hline Unknown & $109 / 10,499(1.0 \%) ; 0.9 \%-1.3 \%$ & $210 / 31,542(0.7 \%) ; 0.6 \%-0.8 \%$ & $0.3 \%(0.2 \%$ to $0.6 \%)$ \\
\hline GCS 3-13 & $178(1.7 \%) ; 1.5 \%-2.0 \%$ & $736(2.3 \%) ; 2.2 \%-2.5 \%$ & $-0.6 \%(-0.9 \%$ to $-0.3 \%)$ \\
\hline
\end{tabular}

$\mathrm{GCS}=$ Glasgow Coma Scale; IQR = interquartile range.

*Injury mechanism severity was defined as follows: Severe = motor vehicle crash with patient ejection, death of another passenger, or rollover; pedestrian or bicyclist without helmet struck by a motorized vehicle; falls greater than 5 feet for patients 2 years and older or falls greater than 3 feet for those younger than 2; or head struck by a high-impact object. Mild = ground-level falls or running into stationary objects. Moderate $=$ any other mechanism.

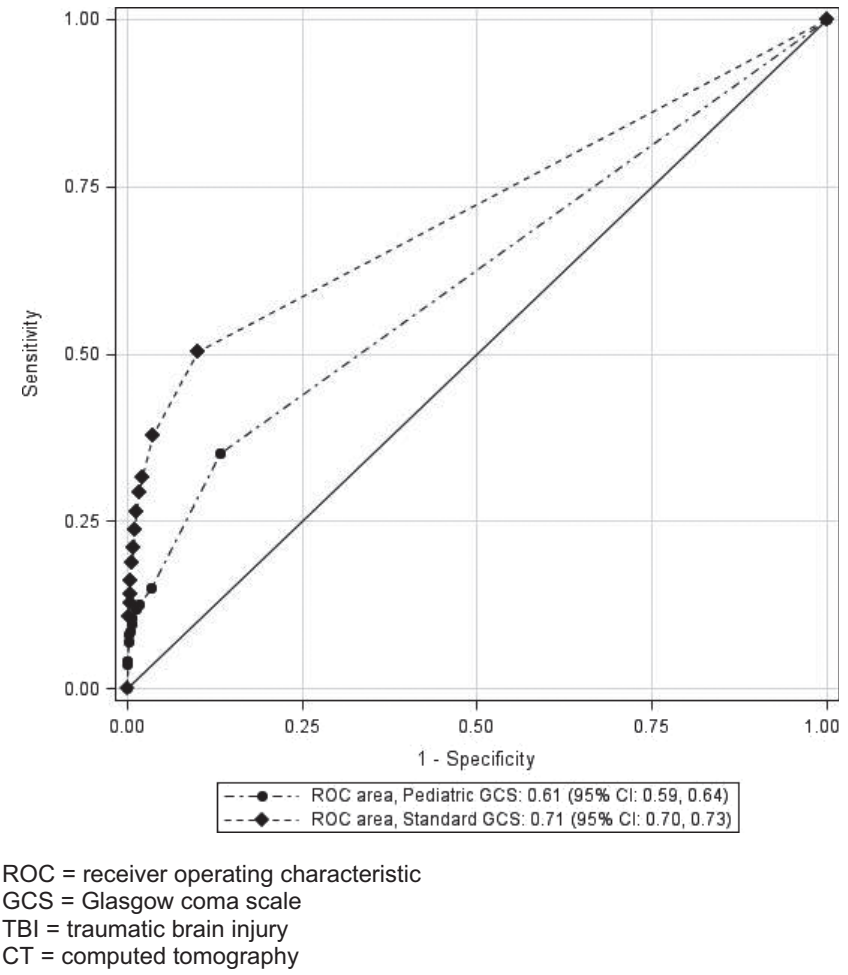

Figure 1. ROC curve for the test accuracy of GCS and TBI on $\mathrm{CT}$. CT = computed tomography; GCS = Glasgow Coma Scale; $\mathrm{ROC}=$ receiver operating characteristic; $\mathrm{TBI}=$ traumatic brain injury.

We were able to contact $79 \%$ of patients discharged home from the ED with a telephone call or mailed followup form. The remaining $21 \%$ had ED chart review, process improvement review, trauma registry review, and morgue review. No patient discharged from the ED was subsequently found to require neurosurgery or died.

\section{DISCUSSION}

In this multicenter study of a large cohort of children with blunt head trauma in the ED setting, the pediatric GCS score for children younger than 2 years performed

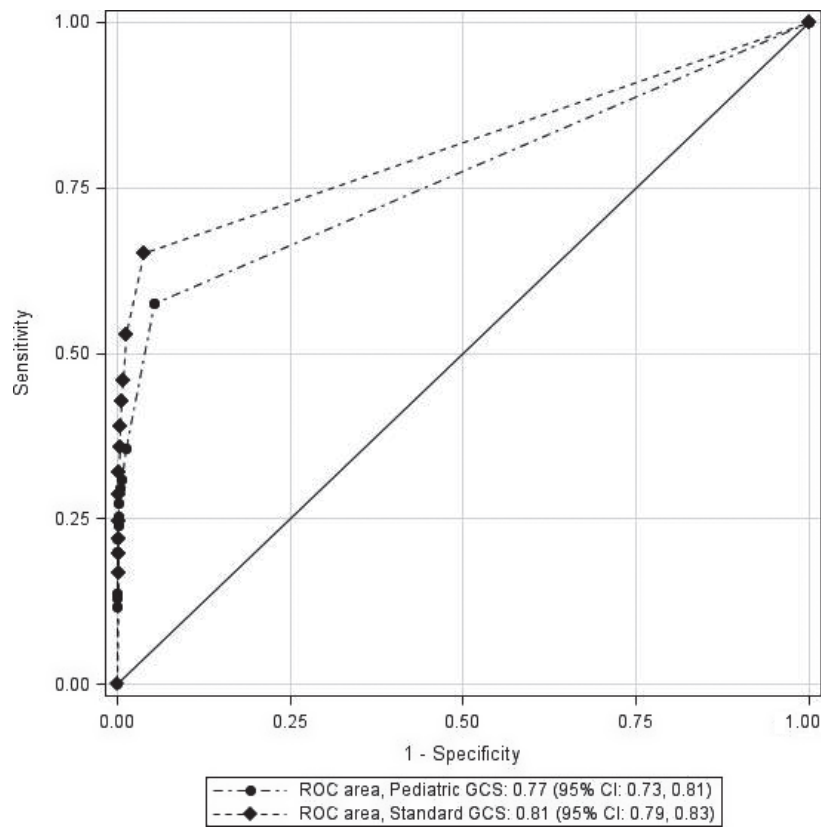

$\mathrm{ROC}=$ receiver operating characteristic GCS = Glasgow coma scale $\mathrm{TBI}=$ traumatic brain injury

Figure 2. ROC curve for the test accuracy of GCS and clinically important TBI. GCS $=$ Glasgow Coma Scale; $\mathrm{ROC}=$ receiver operating characteristic; $\mathrm{TBI}=$ traumatic brain injury.

similarly to the standard GCS in older children for identifying those with ciTBIs. For identifying children with TBI on CT, however, the performance of the pediatric GCS in children younger than 2 years was somewhat less accurate than that of the standard GCS in older children.

These data differ from those of our previous singlesite study that found similar performance of the pediatric GCS and standard GCS for identifying children with TBI on CT and a better performance of the pediatric GCS compared to the standard GCS in identifying children with ciTBIs. ${ }^{7}$ This highlights the need to validate prediction tools in large, multicenter studies. Findings from single-center studies may not always be generalizable to larger, diverse populations. 

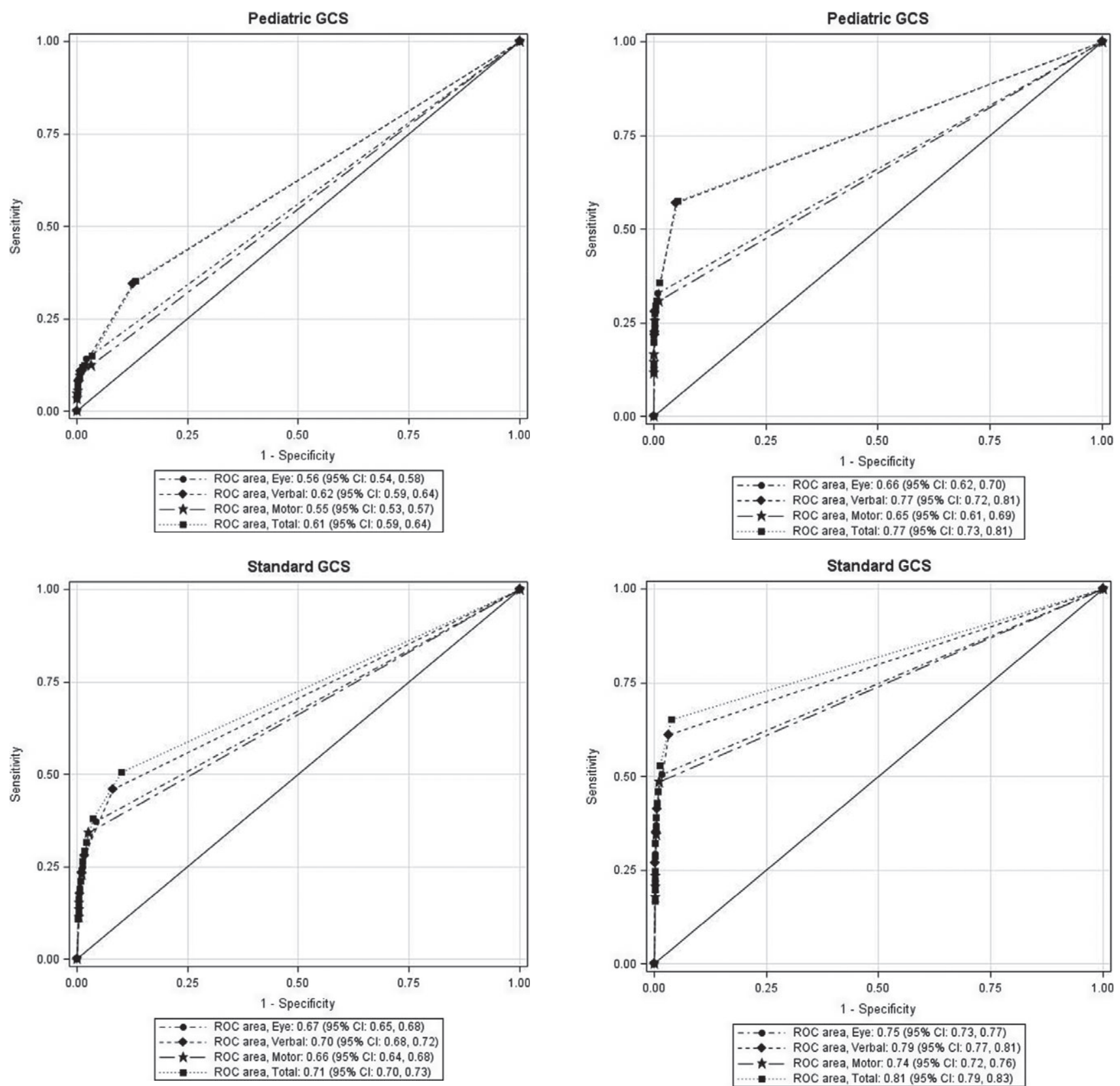

$\mathrm{ROC}=$ receiver operating characteristic

GCS = Glasgow coma scale

$\mathrm{TBI}=$ traumatic brain injury

$\mathrm{CT}=$ computed tomography

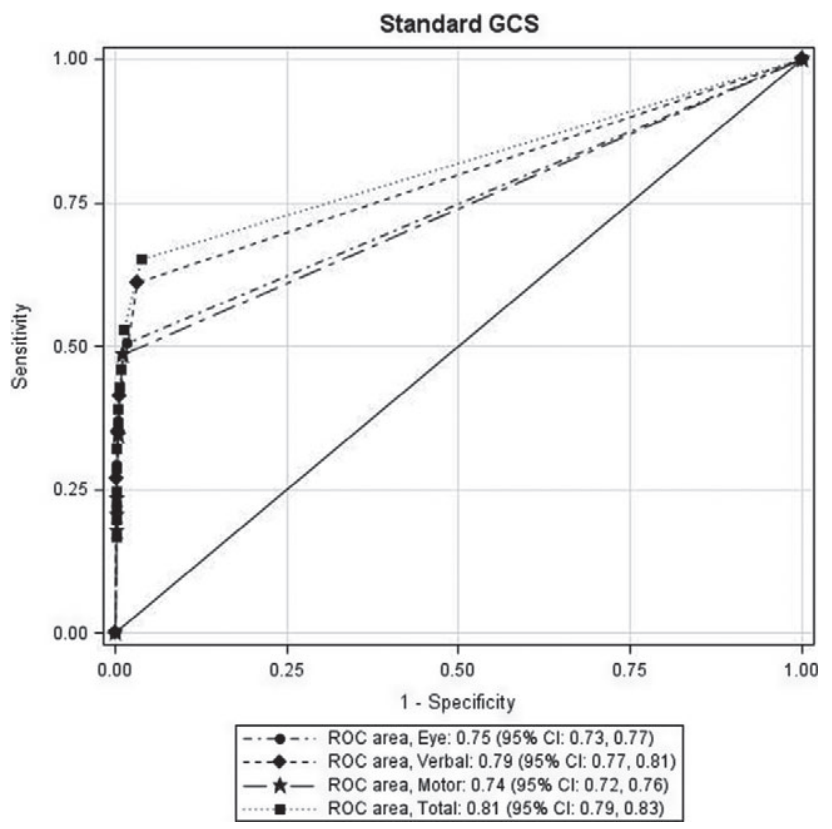

ROC = receiver operating characteristic

GCS = Glasgow coma scale

$\mathrm{TBI}=$ traumatic brain injury

$\mathrm{CT}=$ computed tomography

Figure 3. ROC curve for the test accuracy of the individual GCS components (eye, verbal, motor) and TBI on CT. CT = computed tomography; GCS = Glasgow Coma Scale; $\mathrm{ROC}=$ receiver operating characteristic; $\mathrm{TBI}=$ traumatic brain injury.

Modifications to the standard GCS attempt to create a pediatric GCS score that is helpful in evaluating the level of alertness in head-injured, preverbal children. ${ }^{4}$ 6,10-14 However, none of the previous studies besides one $^{7}$ have evaluated the pediatric GCS score prospectively in the ED setting. The other previous studies were small, retrospective, or conducted in the inpatient/intensive care unit setting. The pediatric GCS

Figure 4. ROC curve for the test accuracy of the individual GCS components (eye, verbal, motor) and clinically important TBI. CT = computed tomography; GCS = Glasgow Coma Scale; $\mathrm{ROC}=$ receiver operating characteristic; $\mathrm{TBI}=$ traumatic brain injury.

score evaluated in the current study is one of the earliest proposed and most widely used. ${ }^{6}$ The scoring for eye opening is similar to that of the standard GCS score; however, modifications are made to four of the five verbal components and two of the six motor response components. These modifications are necessary to evaluate preverbal children who are verbally 
Table 3

Inter-rater Agreement for the Total and Individual GCS Scores Between the Pediatric and Standard GCS Cohorts

\begin{tabular}{|lcc|}
\hline & $\begin{array}{c}\text { Pediatric GCS } \\
\text { Kappa (95\% Cl), } \\
n=379\end{array}$ & $\begin{array}{c}\text { Standard GCS } \\
\text { kappa }(95 \% \mathrm{Cl}), \\
n=1,064\end{array}$ \\
\hline Eye & $0.71(0.42-0.996)$ & $0.86(0.75-0.96)$ \\
Motor & $0.80(0.57-1.00)$ & $0.84(0.70-0.98)$ \\
Verbal & $0.71(0.49-0.93)$ & $0.87(0.78-0.96)$ \\
Total GCS & $0.81(0.63-0.99)$ & $0.90(0.81-0.99)$ \\
\hline GCS = Glasgow Coma Scale. & \\
\hline
\end{tabular}

and developmentally limited and unable to follow commands or answer questions.

Despite its nearly ubiquitous use, the GCS score has certain limitations, including variations in inter-rater reliability, predictive validity, and difficulty in assessment of intubated or sedated patients. ${ }^{15,16}$ To further explain these limitations, researchers have sought to demonstrate predictive abilities of individual components of the GCS score. Prior data in adult patients suggest the motor component is more important than the verbal or eye responses and may be as useful as the total GCS in identifying those with TBI. ${ }^{17}$

In this study, of the three components of the GCS score, the verbal component demonstrated the best test performance for both outcomes in both age cohorts, whereas the motor component demonstrated the worst performance. In adults with severe head injuries, the motor component of the GCS has been shown to be the component most strongly correlated with injury severity and outcomes. ${ }^{18}$ One small trauma registry study of 96 children up to 18 years old with moderate-to-severe head injuries demonstrated similar findings, ${ }^{19}$ as did two more recent retrospective reviews of seriously injured children. ${ }^{20,21}$ In a previous study of children with mostly minor head trauma, however, the verbal and eye components were somewhat more important than the motor component consistently, but this did not achieve statistical significance. ${ }^{7}$ The identification of the verbal component as most strongly correlated with TBI in this study is consistent with these previous data, likely because the great majority of patients in the current study had minor head trauma as defined by GCS scores of 14-15, as was the case for the previous study. ${ }^{7}$ The verbal component of the GCS was the component most likely not to receive the maximum score in both age cohorts. This likely supports its better discriminatory power; however, it is also likely that this variable is the most difficult to assess in preverbal children.

The pediatric GCS used in this study removes one point from the maximal verbal score for the young child who is irritable or cries. On arrival to the ED, children who have experienced traumatic injuries are frequently frightened and in pain; therefore, crying and irritability in this setting are not unexpected. This component of the GCS score is subject to modification by multiple factors including administration of analgesics, parental presence, and time to adjust to the stressful environment of the ED. Therefore, this component of the pediatric GCS is dynamic and changes in this particular GCS component may not reflect actual changes in mental status. In spite of this limitation, the pediatric GCS in the younger patients in this study demonstrated similar test performance for identifying children with ciTBIs as the standard GCS in older children.

The results of this study have pertinent clinical and research implications. This study is the only prospective multicenter study to test the pediatric GCS in preverbal children in the ED setting. The results confirm that clinicians can use the pediatric GCS when evaluating those children presenting to the ED with blunt head trauma. ED clinicians can have confidence that the age-appropriate modified pediatric GCS is as accurate as the standard GCS in identifying children with ciTBI, and the pediatric GCS can be reliably used in clinical research.

\section{LIMITATIONS}

This study has certain limitations. Only $36 \%$ of the study population underwent cranial CT imaging. It is possible that some children who were not imaged may have had traumatic findings on CT. However, clinical outcomes were recorded for all patients, and our main outcome, ciTBI, is a clinical outcome that does not require neuroimaging. In this study we used an age threshold of 2 years to define the population of preverbal patients for whom the pediatric GCS should be applied. This age threshold is somewhat conservative as some children older than 2 years may still be preverbal. Use of the 2-year age cutoff would potentially bias against the accuracy of the standard GCS. Prior studies, however, have used a similar age threshold. ${ }^{7}$ Finally, because we studied only one of the several versions of the pediatric GCS, it is unknown whether other modifications of the GCS for use in preverbal children may enhance its performance.

\section{CONCLUSIONS}

Although the pediatric Glasgow Coma Scale score for evaluation of preverbal children with blunt head trauma evaluated in the ED was somewhat less accurate than the standard Glasgow Coma Scale used for older children for identifying those with traumatic brain injuries on CT, it was equally accurate for identifying children with clinically important traumatic brain injuries. Therefore, clinicians and researchers can confidently use the pediatric Glasgow Coma Scale when evaluating preverbal children for clinically important traumatic brain injuries.

Participating centers and site investigators are listed in alphabetical order: Atlantic Health System/Morristown Memorial Hospital (M. Gerardi); Bellevue Hospital Center (M. Tunik, J. Tsung); Calvert Memorial Hospital (K. Melville); Children's Hospital Boston (L. Lee); Children's Hospital of Michigan (P. Mahajan); Children's Hospital of New York-Presbyterian (P. Dayan); Children's Hospital of Philadelphia (F. Nadel); Children's Memorial Hospital (E. Powell); Children's National Medical Center (S. Atabaki, K. Brown); Cincinnati Children's Hospital Medical Center (T. Glass); DeVos Children's Hospital (J. Hoyle); Harlem Hospital Center (A. Cooper); Holy Cross Hospital (E. Jacobs, A. Foerster); Howard County Medical Center (D. Monroe); Hurley Medical Center (D. Borgialli); Medical College of Wisconsin/Children's Hospital of Wisconsin (M. Gorelick, S. Bandyopadhyay); St. Barnabas Health Care System (M. Bachman, N. Schamban); SUNY-Upstate Medical Center (J. 
Callahan); University of California Davis Medical Center (N. Kuppermann, J. Holmes); University of Maryland (R. Lichenstein); University of Michigan (R. Stanley); University of Rochester (M. Badawy, L. Babcock); University of Utah/Primary Children's Medical Center (J. Schunk); Washington University/St. Louis Children's Hospital (K. Quayle, D. Jaffe); and Women and Children's Hospital of Buffalo (K. Lillis).

We acknowledge the efforts of the following individuals participating in PECARN at the time this study was initiated:

PECARN Steering Committee: N. Kuppermann, Chair; E. Alpern, J. Chamberlain, J. M. Dean, M. Gerardi, J. Goepp, M. Gorelick, J. Hoyle, D. Jaffe, C. Johns, N. Levick, P. Mahajan, R. Maio, K. Melville, S. Miller,* D. Monroe, R. Ruddy, R. Stanley, D. Treloar, M. Tunik, A. Walker. MCHB/EMSC liaisons: D. Kavanaugh, H. Park.

PECARN Data Coordinating Center: M. Dean, R. Holubkov, S. Knight, A. Donaldson.

Data Analysis and Management Subcommittee: J. Chamberlain, Chair; M. Brown, H. Corneli, J. Goepp, R. Holubkov, P. Mahajan, K. Melville, E. Stremski, M. Tunik.

Grants and Publications Subcommittee: M. Gorelick, Chair; E. Alpern, J. M. Dean, G. Foltin, J. Joseph, S. Miller,* F. Moler, R. Stanley, S. Teach.

Protocol Concept Review and Development Subcommittee: D. Jaffe, Chair; K. Brown, A. Cooper, J. M. Dean, C. Johns, R. Maio, N. C. Mann, D. Monroe, K. Shaw, D. Teitelbaum, D. Treloar.

Quality Assurance Subcommittee: R. Stanley, Chair; D. Alexander, J. Brown, M. Gerardi, M. Gregor, R. Holubkov, K. Lillis, B. Nordberg, R. Ruddy, M. Shults, A. Walker.

Safety and Regulatory Affairs Subcommittee: N. Levick, Chair; J Brennan, J. Brown, J. M. Dean, J. Hoyle, R. Maio, R. Ruddy, W. Schalick, T. Singh, J. Wright.

\section{*Deceased}

We thank Rene Enriquez, BS, and Sally Jo Zuspan, RN, MSN, at the PECARN Data Coordinating Center (University of Utah) for their dedicated and diligent work; the research coordinators in PECARN, without whose dedication and hard work this study would not have been possible; and all the clinicians around the PECARN who enrolled children in this study.

\section{References}

1. Teasdale G, Jennett B. Assessment of coma and impaired consciousness. A practical scale. Lancet 1974;2:81-4.

2. Marcin JP, Pollack MM. Triage scoring systems, severity of illness measures, and mortality prediction models in pediatric trauma. Crit Care Med 2002;30: S457-67.

3. Joint Task Force on Advanced Pediatric Life Support, Haller A, Silverman BK. APLS: The Pediatric Emergency Medicine Course. 2nd ed. Elk Grove Village, IL: Joint Task Force on Advanced Pediatric Life Support, 1993.

4. Raimondi AJ, Hirschauer J. Head injury in the infant and toddler. Coma scoring and outcome scale. Childs Brain 1984;11:12-35.
5. Gedeit R. Head injury. Pediatr Rev 2001;22:118-24.

6. James H. Neurologic evaluation and support in the child with an acute brain injury. Pediatr Ann 1986;15:16-22.

7. Holmes JF, Palchak MJ, Conklin MJ, Kuppermann N. Performance of the pediatric Glasgow Coma Scale in children with blunt head trauma. Acad Emerg Med 2005;12:814-9.

8. Kuppermann N, Holmes JF, Dayan PS, et al. Identification of children at very low risk of clinicallyimportant brain injuries after head trauma: a prospective cohort study. Lancet 2009;374:1160-70.

9. Landis JR, Koch GG. The measurement of observer agreement for categorical data. Biometrics 1977;33:159-74.

10. Yager JY, Johnston B, Seshia SS. Coma scales in pediatric practice. Am J Dis Child 1990;144:1088-91.

11. Tatman A, Warren A, Williams A, Powell JE, Whitehouse W. Development of a modified pediatric coma scale in intensive care practice. Arch Dis Child 1977;77:519-21.

12. Simpson DA, Cockington RA, Hanieh A, Raftos J, Reilly PL. Head injuries in infants and young children: the value of the Paediatric Coma Scale. Review of literature and report on a study. Childs Nerv Syst 1991;7:183-9.

13. Reilly PL, Simpson DA, Sprod R, Thomas L. Assessing the conscious level in infants and young children: a paediatric version of the Glasgow Coma Scale. Childs Nerv Syst 1988;4:30-3.

14. Morray JP, Tyler DC, Jones TK, Stuntz JT, Lemire RJ. Coma scale for use in brain-injured children. Crit Care Med 1984;12:1018-20.

15. Gill MR, Reiley DG, Green SM. Interrater reliability of Glasgow Coma Scale scores in the emergency department. Ann Emerg Med 2004;43:215-23.

16. Riechers R, Ramage A, Brown W, et al. Physician knowledge of the Glasgow Coma Scale. J Neurotrauma 2005;22:1327-34.

17. Healey C, Osler T, Rogers F, et al. Improving the Glasgow Coma Scale score: motor score alone is a better predictor. J Trauma 2003;54:671-80.

18. Choi SC, Narayan RK, Anderson RL, Ward JD. Enhanced specificity of prognosis in severe head injury. J Neurosurg 1988;69:381-5.

19. Van de Voorde P, Sabbe M, Rizopoulos D, et al. Assessing the level of consciousness in children: a plea for the Glasgow Motor subscore. Resuscitation 2008;76:175-9.

20. Acker SN, Ross JT, Partrick DA, Nadlonek NA, Bronsert M, Bensard DD. Glasgow motor scale alone is equivalent to Glasgow Coma Scale at identifying children at risk for serious traumatic brain injury. J Trauma Acute Care Surg 2014;77:304-9.

21. Fortune PM, Shann F. The motor response to stimulation predicts outcome as well as the full Glasgow Coma Scale in children with severe head injury. Pediatr Crit Care Med 2010;11:339-42. 